\title{
O LETRAMENTO LITERÁRIO NO ENSINO MÉDIO EM GOIÁS: CRÍTICA DAS ORIENTAÇÕES E REFERÊNCIAS CURRICULARES ESTADUAIS
}

\author{
Cleiry de Oliveira Carvalho \\ CÁsSio TAVARES \\ Universidade Federal de Goiás (UFG), Goiânia, Goiás, Brasil
}

\begin{abstract}
ResUmo: O objetivo aqui foi cotejar os documentos divulgados pela Secretaria de Estado de Educação, Cultura e Esporte de Goiás que visam apresentar orientações curriculares para o Ensino Médio com outros documentos relacionados, tais como os PCNs e as OCNs. O resultado desse cotejamento de documentos demonstra a ausência de discussão ou perspectiva para o letramento literário nas orientações estaduais para o Ensino Médio. Mas não só: o uso da literatura como pretexto para o ensino de gramática e língua portuguesa é visível nas matrizes de conteúdos.

Palavras-chave: Literatura. Ensino Médio. Currículo. Políticas públicas em Educação.
\end{abstract}

A partir de discussões sobre educação literária e letramento, queremos aqui refletir sobre o ensino de literatura no estado de Goiás. Por meio do cotejamento de documentos divulgados pela Secretaria de Estado de Educação, Cultura e Esporte de Goiás que visam apresentar orientações curriculares para o Ensino Médio, propomos - com o intuito de verificar em que medida os documentos produzidos em Goiás inovam ou, ainda, se acompanham ou se afastam dos documentos federais - verificar como o estado de Goiás prevê a presença da Literatura no Ensino Médio. Dado esse recorte, o foco da análise é o tratamento dado ao conteúdo literário nos documentos estaduais analisados. É certo que tanto as OCNs (BRASIL, 
2006) quanto os PCNs (BRASIL, 1999) merecem estudo por si mesmos, mas o interesse neles é aqui subsidiário do recorte adotado - o cotejo do geral (parâmetros e orientações nacionais) com o particular (documentos estaduais análogos).

A referência principal no cotejo serão as $\mathrm{OCN}$ s e não os $\mathrm{PCN}$ s devido ao fato de que as $\mathrm{OCN}$ s se propõem a suprir o que seria, para todos os efeitos práticos, uma "ausência" da Literatura nos PCNs - em algum momento será oportuno trazer os $\mathrm{PCNs}$, mas as $\mathrm{OCN}$ s serão a referência principal. A análise dos documentos estaduais começará pelos Referenciais Curriculares - Ensino Médio do Estado de Goiás, ainda na versão preliminar, embora sua gestação tenha tido início no final de 2008 (Corem). Sua ambição, segundo o que se tem na apresentação do documento, seria a de "consolidar os sinais de uma política pública que anunciava o tempo oportuno à discussão e elaboração dos referenciais curriculares para o ensino médio". Também será analisado o documento Currículo Referência da Rede Estadual de Educação de Goiás, também ainda em versão experimental. Por fim, será abordado o Relatório de análise de propostas curriculares de ensino fundamental e ensino médio, coordenado por Maria das Mercês Ferreira Sampaio.

Ao examinarmos o volume Linguagens, códigos e suas tecnologias, das OCNs (Brasil, 2006), e considerando sua dimensão política, chama a atenção o peso de seus leitores críticos - trazendo para o primeiro plano a demanda de conhecimentos de literatura, o documento recebe aval de Lígia Chiappini Moraes Leite e Haquira Osakabe. A justificativa do documento é contundente:

As orientações que se seguem têm sua justificativa no fato de que os PCN do ensino médio, ao incorporarem no estudo da linguagem os conteúdos de Literatura, passaram ao largo dos debates que o ensino de tal disciplina vem suscitando, além de negar a ela a autonomia e a especificidade que lhe são devidas.

\section{$[\ldots]$}

Embora concordemos com o fato de que a Literatura seja um modo discursivo entre vários (o jornalístico, o científico, o coloquial etc.), o discurso literário decorre, diferentemente dos outros, de um modo de construção que vai além das elaborações linguísticas usuais, porque de todos os modos discursivos é o menos pragmático, o que menos visa a aplicações práticas. Uma de suas marcas é sua condição limítrofe, que outros denominam transgressão, que garante ao participante do jogo da leitura literária o exercício da liberdade, e que pode levar a limites extremos as possibilidades da língua [...] (BRASIL, 2006, p. 49). 
Para os autores "A disciplina [Literatura], um dos pilares da formação burguesa humanista, sempre gozou de status privilegiado ante as outras ${ }^{1}$, dada a tradição letrada de uma elite que comandava os destinos da nação" (BRASIL, 2006 , p. 51 - destaque nosso). E, talvez para apontar que a literatura é de fato um privilégio de classes burguesas, os autores fazem uso do depoimento de uma mãe de aluno sobre o que ela pensa ser arte. Linhas depois o que se tem é o seguinte: "por que ainda há Literatura no currículo do ensino médio se seu estudo não incide diretamente sobre nenhum dos postulados desse mundo hipermoderno?" (BRASIL, 2006, p. 52). E a crítica aos PCNs vai se materializando ao longo do documento: os PCNs poriam "ênfase radical no interlocutor, chegando ao extremo de erigir as opiniões do aluno como critério de juízo de uma obra literária, deixando, assim, a questão do 'ser ou não ser literário' a cargo do leitor" (BRASIL, 2006, p. 58).

Os PCNs - Parâmetros Curriculares Nacionais (Ensino Médio), no seu volume 2, que trata das "Linguagens, Códigos e suas Tecnologias" especialmente "Conhecimentos de Língua Portuguesa" - preveem uma nova maneira de educar (vinculada ao mundo tal como ele é, e não só como ensina a escola), uma linguagem fácil de entender para que os alunos desenvolvam a capacidade de argumentar e defender seus pontos de vista. Assim, quanto mais contato o aluno tem com textos diferentes, mais facilidade ele terá para responder suas questões imediatas. Os PCNs - "Conhecimentos de Língua Portuguesa" trazem na sua concretização a seguinte constatação:

A história da literatura costuma ser o foco da compreensão do texto; uma história que nem sempre corresponde ao texto que lhe serve de exemplo. O conceito de texto literário é discutível. Machado de Assis é literatura, Paulo Coelho não. Por quê? As explicações não fazem sentido para o aluno (BRASIL, 1999, p. 34).

Os organizadores dos PCNs, ao prepararem essa exposição de como os textos literários são recebidos pelos alunos, solicitam que estes separem de um bloco de textos (poemas de Pessoa e Drummond, contas de telefone, cartas de bancos) o que é literário e o que não é literário. Um dos grupos não faz nenhuma separação e é questionado. A resposta é desconcertante:"todos são não-literários, porque servem apenas para fazer exercícios na escola" (BRASIL, 1999, p. 34). E Drummond? Os alunos respondem: “Drummond é literato, porque vocês afirmam que é, eu não concordo. Acho ele um chato. Por que Zé Ramalho não é literatura? Ambos são poetas, não é verdade?" (BRASIL, 1999, p. 34) E os organizadores perceberam que para os alunos as classificações "literário e não literário" impostas pela escola não lhes 
possibilitam estabelecer as relações de leitura literária e leitura não literária porque, para os alunos, todos são textos para exercícios na escola. Parecenos que a escola peca duas vezes. Primeiro, por não dar conta do ensino dos textos considerados literários; segundo, por não ensinar, ainda, a leitura dos não literários. Isto porque, se o objetivo da escola é possibilitar a formação de leitores críticos e não apenas ensiná-los a decodificar sintagmas, por que não ensiná-los a reconhecer um texto literário e um não literário?

A dificuldade é que uma aprendizagem significativa dessa distinção depende de ela fazer sentido na experiência estética dos discentes, o que, como mostra o exemplo do parágrafo anterior, não é possível no quadro da distinção estabelecida em uma tradição elitista. Tampouco resolve o caso o afrouxamento permissivo da distinção (o que seria somente uma fuga ao problema de fundo): seria preciso partir de uma crítica rigorosa da própria ideia de literatura.

Enfatizamos que a realização dos PCNs em sua integralidade exigiria uma escola diferente: com bibliotecas perenemente abertas e atualizadas, bibliotecários e professores bem preparados para o ensino, professores bem respaldados com recursos materiais, professores bem remunerados, com tempo para preparar aulas em que fosse possível a participação do discente e a prática de metodologias integrativas ou interdisciplinares. Defendemos que é necessário dar condições humanas para que a escola consiga fazer o papel mediador entre leitor e texto.

Mas se as OCNs surgem na crítica aos PCNs, resta entender se as OCNs estão no caminho adequado ou também têm seus problemas. Claro, o problema dos PCNs, na nossa leitura, não se restringe ao afrouxamento da distinção entre o literário e não literário. Mas observamos, nas OCNs, vários pontos que contradizem a política que defende a"inclusão" da Literatura para todos. Diz o documento: "Diríamos mesmo que têm mais direito [à fruição da literatura] aqueles que têm sido, por um mecanismo ideologicamente perverso, sistematicamente mais expropriados de tantos direitos, entre eles até o de pensar por si mesmos" (BRASIL, 2006, p. 53). Ótimo, isso mesmo. Mas como está prevista a garantia desse direito? Não é possível que seja assim:

Se consideramos que o texto literário é por excelência polissêmico, permitindo sempre mais de uma interpretação, e se admitimos que cada leitor reage diferentemente em face de um mesmo texto, pensamos que o passo inicial de uma leitura literária seja a leitura individual, silenciosa, concentrada e reflexiva. Esse momento solitário de contato quase corporal entre o leitor e a obra é imprescindível, porque a sensibilidade é a via mais eficaz de aproximação do texto. Mediante o isolamento e o silêncio, a leitura individual 
proporciona ao aluno a experiência literária de um texto que pode atingir sua subjetividade de maneira inusitada e certamente diferente da maneira como atinge a subjetividade do colega. Como espaço preferencial de manifestação das diferenças, a escola, "da sala de aula ao recreio, pode proporcionar o espaço-tempo da releitura da própria leitura pelo confronto com a leitura alheia, pode potencializar o individual pelo coletivo e vice-versa nas conversas e debates da leitura de cada aluno ou aluna" (CHIAPPINI, 2005, p. 1). Entendemos, pois, que a atividade coletiva da leitura literária dá-se num segundo momento, sendo indispensável passar pela leitura individual (BRASIL, 2006, p. 60 - destaques nossos).

Esse documento federal que requer a presença da Literatura de maneira mais expressiva do que o apresentado nos PCNs tem a "nobre" visão de apresentar um leitor solitário, uma leitura individual, um espaço tomado pelo silêncio. Depois, e somente depois, é que a literatura deve ser confrontada, dialogada, exposta ao e no coletivo. Não é essa uma visão burguesa da Literatura? Como seria uma prática de leitura literária não burguesa? Não apontam as OCNs para o papel da apropriação do texto literário para dar alguma "alegriazinha" aos pobres homens que costumeiramente não tem acesso à literatura erudita? Quais são as condições materiais de que esses pobres "coitados" desprovidos de obras literárias e privados de "prazer estético" dispõem para fazer suas leituras em ambiente silencioso e individualmente? Não é perfeitamente desejável e eficiente a leitura em grupo, a leitura em voz alta, a leitura compartilhada? Não seria eficaz pensar, por exemplo, na leitura dos contos de Guimarães Rosa em voz alta, para um grupo que pudesse parar e discutir, consultar, retornar e retomar quando fosse necessário? A literatura na dramaturgia não pede ainda um leitor em voz que ecoa? Ou até que ponto os autores das OCNs também se apresentam vestidos dos seus preconceitos ao tratarem de questões como o erudito e o não erudito? Vejamos:

[...] de um lado, o professor que só trabalha com autores indiscutivelmente canônicos, como Machado de Assis, por exemplo, utilizando-se de textos críticos também consagrados: caso do professor considerado autoritário, conservador, que aprendeu assim e assim devolve ao aluno; de outro lado, o professor que lança mão de todo e qualquer texto, de Fernando Pessoa a raps, passando pelos textos típicos da cultura de massa: caso do professor que se considera libertário (por desconstruir o cânone) e democrático (por deselitizar o produto cultural). Será? - perguntamo-nos. Ainda acompanhando o raciocínio de Chiappini, se existe o professor "conservador" que ignora outras formas de manifestação artística, não haveria, de outro lado, na atitude "democrática", e provavelmente cheia de boas intenções, um certo desrespeito às manifestações populares, sendo condescendente, paternalis- 
ta, populista, "sem adotar o mesmo rigor que se adota para a cultura de elite"? Ou, acrescentaríamos nós, não haveria demasiada tolerância relativamente aos produtos ditos "culturais", mas que visam somente ao mercado? Se vista assim, essa atitude não seria libertária ou democrática, mas permissiva. Pior ainda: não estaria embutido nessa escolha o preconceito de que o aluno não seria capaz de entender/fruir produtos de alta qualidade? (BRASIL, 2006, p. 56 - destaques nossos).

De fato, nesses dois extremos temos uma atitude autoritária elitista e uma atitude complacente paternalista. Mas será que buscar o meio-termo sem pôr em discussão o fundamento das dualidades "erudito"/"popular" e "canônico"/"não canônico" é suficiente? Não é, como se pode concluir pelo exame dessa mesma citação, em que vemos os autores localizarem essas oposições no eixo da qualidade estética, sugerindo que fora da esfera canônica os alunos ficariam privados de "fruir produtos de alta qualidade". Mas a qualidade estética pode ser problematizada tanto no campo erudito quanto no popular: é discutível o valor estético de um Casimiro de Abreu, que já foi presença obrigatória no cânone escolar; por outro lado, seria difícil argumentar que não tem valor estético a obra de alguns sambistas sem muita escolarização, como o pedreiro Cartola. A qualidade estética não pode ser discutida, por exemplo, a propósito do gênero rap? Com efeito, essa confusão que associa cânone a alta qualidade é produto daquele mesmo preconceito que, na passagem citada, as OCNs procuram denunciar e combater. Mas os autores não se detêm para examinar com maior minúcia a questão - seguem seu curso, apoiando-se na autoridade de Chiappini, Candido, Zilberman, Magda Soares etc., retomam os PCNs e os $\mathrm{PCN}+$, para enfim apresentar a solução do momento: "faz-se necessário e urgente o letramento literário: empreender esforços no sentido de dotar o educando da capacidade de se apropriar da literatura, tendo dela a experiência literária" (BRASIL, 2006, p. 55). De fato, é necessário e urgente o letramento literário; mas os termos em que esse letramento pode ou deve ser levado a cabo parecem longe de estar resolvidos. E a mãe do aluno surge revigorante: "'Arte é um que-fazer que inventa uma alegriazinha'" (BRASIL, 2006, p. 55).

Os autores preocupados em "salvar" o possível estrago dos PCNs e PCN+ apontam e discutem os caminhos tortuosos dados por esses documentos, retomam teóricos da literatura e eis uma nova fórmula, clara, direta: "Quanto mais profundamente o receptor se apropriar do texto e a ele se entregar, mais rica será a experiência estética, isto é, quanto mais letrado literariamente o leitor, mais crítico, autônomo e humanizado será" (BRASIL, 2006, p. 60 - destaque nosso). Não é essa uma visão estereotipada e de 
pensamento raso? E, como já dito, a "salvação" do leitor de literatura é primeiro individual: "Mediante o isolamento e o silêncio, a leitura individual" (BRASIL, 2006, p. 60 - destaque nosso). Para os autores, é necessário que aconteça uma primeira leitura nas condições apontadas e, somente após esse primeiro envolvimento do aluno com a obra, vigorará o embate na sala de aula. Como já dito, são possíveis outros caminhos, menos burgueses e mais coletivos.

Os poucos recortes aqui apresentados servem a um único propósito: verificar em que medida os documentos produzidos em Goiás inovam ou, ainda, refutam os documentos federais, para avaliar como o estado prevê a presença da Literatura no ensino em Goiás.

Como se configuram essas diretrizes no cerrado em questão? O documento tem por título Referenciais Curriculares - Ensino Médio do Estado de Goiás. Nas considerações iniciais tem-se:

As primeiras tarefas circunscreveram-se em torno de estudos para o embasamento teórico comum a todas as disciplinas: legislação federal e estadual, parâmetros curriculares nacionais, bem como a interligação desses fundamentos com um currículo interdisciplinar em sua totalidade, entre outros. Depois de ampla discussão, a Comissão se subdividiu em 15 grupos em consonância com as disciplinas componentes das quatro áreas curriculares, com o objetivo de aprofundar as especificidades de cada conteúdo. O estudo guia desse momento foi a pesquisa de fundamentação de cada disciplina na contemporaneidade. Desse modo, elaborou-se a defesa da disciplina, composta por uma revisitação histórica em cada um dos ramos do saber ministrados no ensino médio. Depois disso, aconteceu o primeiro momento de síntese: a discussão com professores em exercício para escolha dos conteúdos, por isso no início de dez/2008, realizou o I Seminário - Ressignificando o Ensino Médio (GOIÁS, 2009, p. 4).

O documento é composto de cinco partes, das quais nos interessa a primeira: "Referencial curricular de Língua Portuguesa para o Ensino Médio". Mas, antes, um olhar rápido pelo documento como um todo e com um único objetivo: verificar as ocorrências da palavra literatura (e seus derivados). 0 documento apresenta numeração de página de 1 a 284. No entanto, traz 239 páginas, pois faltam as páginas de número 166 até 210 . E nessas 239 páginas são dez ocorrências da palavra literatura, no documento inteiro, sendo três delas na especificação das formações de professores que contribuíram com a feitura do documento. As outras sete aparecem na seguinte ordem:

No tópico "Objetivo do Ensino de Língua Portuguesa no Ensino Médio", temos o uso da palavra em:"Não se pode negar que a palavra 'gênero' (cf. Soares, 1989) já circulava nos documentos oficiais do século XIX, tendo sido 
bastante utilizada pela retórica e pela literatura com acepção designadamente literária" (GOIÁS, 2009, p. 13 - destaque nosso). Ainda tem-se nesse tópico outra ocorrência:

Assim, os gêneros são agrupados em dois grupos: os gêneros primários - ligados às relações cotidianas (conversa face a face, linguagem familiar, cotidiana etc.; em um ângulo mais direto, esses gêneros são os mais comuns no dia a dia do falante e os secundários - mais complexos (discurso científico, literatura, jornalístico etc.) referem-se a outras esferas de interação social, mais bem desenvolvidas (GOIÁS, 2009, p. 14 - destaque nosso).

Note-se que Bakhtin aparece de modo esquemático, podendo acarretar problemas se o professor partir desse documento sem aprofundar o estudo desses gêneros. Passemos adiante. A palavra aparece também no tópico "A Filosofia e seu caráter específico", na ementa, da seguinte maneira:

Fornecer elementos para a compreensão da leitura dos textos filosóficos, o reconhecimento dos problemas filosóficos - tanto os que se originam da própria circunstância individual e social do aluno quanto aqueles contidos nas outras áreas da atividade humana, como nas ciências, nas artes e na literatura - e dar subsídios para que, com sua própria reflexão e com os conhecimentos filosóficos adquiridos, o estudante possa se integrar na comunidade de forma crítica e ativa, reconhecendo os desafios que devem ser superados para o exercício pleno de sua cidadania (GOIÁS, 2009, p. 136 - destaque nosso).

Seguindo, vemos, nos objetivos do tópico acima, o seu caráter específico:

* Apontar os vínculos estreitos entre as artes (incluindo a literatura, a poesia e o teatro) e as ideias filosóficas.

* Trabalhar a geograficidade filosófica do saber, isto é, a relação entre o desenvolvimento humano nas diversas regiões e as manifestações culturais dos diversos povos, considerando-se as artes, a literatura e a filosofia (GOIÁS, 2009, p. 136-137 - destaques nossos).

A penúltima ocorrência aparece no tópico "Caracterização do Ensino Religioso no Estado de Goiás" e tem sua entrada no eixo "IV-Literatura sagrada e símbolos religiosos: refere-se aos livros sagrados das religiões monoteístas e também orais, culturais e simbólicas, dos cultos afro-brasileiros de matriz africana e dos indígenas brasileiros" (GOIÁS, 2009, p. 219). E a última está presente no plano "Conteúdos Básicos para o $1^{\circ}$ Ano", a ser desenvolvido 
no tópico "A Era Vargas: autoritarismo, Estado e nação": "Analisar o papel da propaganda oficial para a difusão do novo ideário nacional, utilizando os meios de comunicação (rádio) e as expressões artísticas (música, literatura, cinema)" (GOIÁS, 2009, p. 236 - destaque nosso).

Nenhuma das ocorrências remete à disciplina Literatura, nenhuma. Mas o documento apresenta um tópico que pode, de alguma forma, atender a essa demanda. Eis o tópico: "Objetivo do Ensino de Língua Portuguesa no Ensino Médio". Como já apresentado, nesse tópico foi possível constatar a palavra literatura, no mesmo fragmento tem-se a presença da palavra "literária". Diz o fragmento:

[...] e pela literatura com acepção designadamente literária.

Segundo Marcuschi (2002), a expressão 'gênero' sempre esteve, na tradição ocidental, especialmente ligada aos gêneros literários, mas já não é mais assim, como lembra Swales (1990, p.33), ao dizer que 'hoje, gênero é facilmente usado para referir-se à categoria distintiva de discurso de qualquer tipo, falado ou escrito, com ou sem aspirações 'literárias' (GOIÁS, 2009, p. 13 - destaques nossos).

Também chama a atenção o referencial teórico usado no documento para discutir língua portuguesa:

BRASIL. Orientações Curriculares para o Ensino Médio: linguagens, códigos e suas tecnologias. Brasília: Ministério da Educação, 2006.

BECHARA, E. Moderna gramática portuguesa. Rio de Janeiro: Lucerna, 1985.

TERRA, Ernani. Linguagem, língua e fala. São Paulo: Scipione,1997.

TRAVAGLIA, Luiz Carlos. Gramática e interação: uma proposta para o ensino de gramática no 1.0 e 2.o graus. São Paulo: Cortez,1996.

A presença da gramática é valorizada em detrimento da Literatura. $E$ as OCNs, mesmo sendo elaboradas para suprir a falta de clareza, para muitos, do ensino de literatura nos PCNs, não são suficientes para atender nem mesmo às demandas propostas no documento. Na tentativa de encontrar a presença da literatura, ainda que a existência na condição de disciplina não esteja materializada nesse documento, a busca passa a ter seu foco na área de Artes. O tópico "Ensino de Teatro", inserido nas Artes, tem no seu referencial os seguintes autores:

GASSET, J. Ortega. Y. A ideia do teatro. São Paulo: Perspectiva, 1999, p.07 
KOUDELA, I. D. Jogos teatrais. São Paulo: Perspectiva/Edusp, 1991.

ROUBINE, J. J. A linguagem da encenação teatral. 1880-1980. Tradução e apresentação de Yan Michalski. 2. ed. Rio de Janeiro: Jorge Zahar, 1992.

Mas, nesse tópico, a presença do teatro parece destinada a atender à demanda de formação teatral e é preciso apontar a ausência de qualquer atenção dirigida à dramaturgia como objeto literário. A tarefa agora é conhecer o documento Currículo Referência da Rede Estadual de Educação de Goiás. Também esse documento está em fase experimental. $\mathrm{O}$ documento tem início com uma apresentação e dela destacamos:

A Secretaria de Estado da Educação de Goiás compreende que construir um currículo referência é uma forma de indicar a busca da superação dos problemas e dificuldades que a Educação Básica atualmente enfrenta em todo o país e em nosso estado, fortalecendo assim um conjunto de ações importantes para a consolidação de uma aprendizagem significativa do estudante.

Para a construção de um currículo que refletisse o pensamento e os anseios da Rede aconteceram espaços que oportunizaram a participação dos educadores. Em outubro e novembro de 2011 foi elaborado o documento base no qual fomentou as discussões por todo o período da bimestralização, resultando, com a participação de 500 professores, na apreciação e validação prévia do documento (GOIÁS, s/d, p. 12).

Apesar de o documento informar que está em constante revisão, não tem uma data a versão em uso. Mas o ano de 2012 aparece em seu texto como o ano das sistematizações e apresentações finais do documento.

Em outubro de 2012 divulgou-se, junto às SREs, a versão preliminar do documento, proporcionando a análise e o aprimoramento de cada componente curricular pelos professores das Unidades Educacionais.

Em novembro e dezembro de 2012, a Seduc sistematizou as contribuições, revisou a versão preliminar e realizou um novo encontro com RCCs divididos por áreas para exposição da Versão Final do Documento (GOIÁS, s/d, p. 12).

Essa apresentação do documento é encerrada com a informação de ser sempre possível uma retomada do documento apresentado. A ideia do trânsito constante parece, pelo visto, não obrigar um registro datado de versões.

Após a apresentação, chegamos ao tema específico no tópico "Língua Portuguesa no Ensino Médio". Mas observemos de passagem que 
foi possível constatar a presença de usos da literatura brasileira já no Ensino Fundamental. Chamamos a atenção para duas ocorrências presentes nas Expectativas de Aprendizagens do $9^{\circ}$ ano do EF, no Currículo Referência de História. Por exemplo:

Conhecer e compreender os fatores que expliquem os movimentos político-religiosos no Brasil (por exemplo, Canudos, Contestado, Santa Dica) a partir de uma seleção de textos sobre o Sertão (Euclides da Cunha, Monteiro Lobato, Hugo de Carvalho Ramos, Bernardo Élis e outros) (GOIÁS, s/d, p. 260 - destaques nossos).

Ou seja, a literatura brasileira aparece. É claro que a mera menção de alguns textos literários não garante uma preocupação real com o letramento literário. Mas já pode ser um sinal. É o que sugerem as Expectativas de Aprendizagens do $8^{\circ}$ ano do EF, também no Currículo Referência de História: "Utilizar a leitura, a compreensão e a interpretação de textos diversos para tornar-se um leitor competente e possibilitar o letramento linguístico, literário, social, científico" (GOIÁS, s/d, p. 259 - destaque nosso). Observa-se aí, pois, certa dispersão da questão literária em outros conteúdos.

Passemos enfim ao caso do EM, cuja estrutura, rigorosamente a mesma para todas as séries e para os quatro bimestres de cada ano letivo, pode ser exemplificada, na ilustração abaixo, pelo programa do $4^{\circ}$ bimestre da 2a série do EM (GOIÁS, s/d, p. 62):

\begin{tabular}{|c|c|c|c|}
\hline \multicolumn{4}{|c|}{ 2a SÉRIE/ ENSINO MÉDIO } \\
\hline \multirow{5}{*}{ 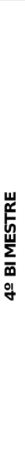 } & EXPECTATIVAS DE APRENDI ZAGEM & $\begin{array}{c}\text { EIXOS } \\
\text { TEMÁTCOS }\end{array}$ & CONTEÚDOS \\
\hline & $\begin{array}{l}\text { - Dialogar sobre as diferenças entre charges e cartuns. } \\
\text { - Debater sobre temas representados nas charges e cartuns. } \\
\text { - Dialogar sobre os efeitos de humor e ironia nas charges e cartuns. } \\
\text { criança, ao velho, nos gêneros em estudo. }\end{array}$ & $\begin{array}{l}\text { Prática de } \\
\text { Oralidade }\end{array}$ & \multirow{4}{*}{$\begin{array}{l}\text { - Romances. } \\
\text { - Poemas. } \\
\text { - Charges. } \\
\text { - Cartuns. }\end{array}$} \\
\hline & $\begin{array}{l}\text { - Ler romances, poemas, charges e cartuns, utilizando diferentes estratégias de leitura como mecanismos de } \\
\text { interpretação de textos: } \\
\checkmark \text { Formular hipóteses (antecipação e inferência). } \\
\checkmark \text { Verificar hipótese (seleção e checagem). } \\
\text { - Ler associativa e comparativamente os gêneros em estudo, observando forma, conteúdo, estilo e função social. }\end{array}$ & $\begin{array}{c}\text { Prática de } \\
\text { Leitura }\end{array}$ & \\
\hline & $\begin{array}{l}\text { - Produzir poemas, charges, cartuns e reconto de capítulo de romance, observando os elementos constitutivos dos } \\
\text { gêneros em estudo (forma, estilo e conteúdo) em função das condiçốes de produção. }\end{array}$ & $\begin{array}{c}\text { Prática de } \\
\text { Escrita }\end{array}$ & \\
\hline & $\begin{array}{l}\text { - Refletir sobre orações coordenadas nos gêneros em estudo. } \\
\text { - Refletir sobre avaliação linguística nos gêneros em estudo. } \\
\text { - Refletir sobre o uso da pontuação nos gêneros em estudo. } \\
\text { - Refletir sobre a ortografia nos gêneros em estudo. } \\
\text { - Refletir sobre o emprego dos acentos gráficos e da crase nos gêneros em estudo. } \\
\text { - Refletir sobre o Pré-Modernismo em suas dimensões histórica, linguística e social. } \\
\text { - Reescrever poemas, charges, cartuns e reconto de capítulo de romance produzidos (coletiva e individualmente). }\end{array}$ & $\begin{array}{l}\text { Prática de } \\
\text { Análise da } \\
\text { Língua }\end{array}$ & \\
\hline
\end{tabular}

Fonte: GOIÁS. Currículo Referência da Rede Estadual de Educação de Goiás (s/d)

Posto o caráter esquemático da ilustração, convém observar que, em que pese o referencial teórico citado no documento, ele não apresenta 
informações suficientes, que possam nortear o leitor quanto aos cuidados e procedimentos necessários à realização eficaz das atividades implicadas. É claro, não é possível negar, a literatura está presente - o que cumpre discutir é o como (não é do escopo deste trabalho verificar o uso concreto que fazem dos materiais literários os professores em sala de aula, mas cumpre avaliar o uso prescrito pelo documento para esses materiais).

Observados a dimensão estética e o caráter ficcional de que são dotados os cartuns e as charges, é forçoso reconhecer neles a natureza literária - o que nos leva à constatação de que todas as atividades do bimestre, em todos os eixos temáticos, tomam por objeto a literatura, que na tabela domina a coluna dos conteúdos ${ }^{2}$. São por isso enfatizados os aspectos estéticoliterários associados? A dúvida ganha força quando se vê, na descrição do eixo "Prática de análise da língua", que persiste a instrumentalização - ainda tão prevalente, embora já tão condenada - do texto literário para ensino de conhecimentos gramaticais. $O$ texto, seja de que gênero for, literário ou não, quando tratado como repositório de exemplos de pontuação, ortografia, acentos gráficos, crase, orações coordenadas e subordinadas, perde sua função social e tem sua existência reduzida ao terreno da pura decodificação, em exercícios que frequentemente só fazem sentido como tarefa escolar, via de regra chatos e ineficientes - eis o texto literário tornado não literário, pois transformado em tarefa escolar, como atesta o exemplo apresentado pelos PCNs e comentado na página acima.

Pode parecer má vontade nossa destacar esse aspecto, dado que trata-se apenas do quarto e último eixo temático, a que se chega depois de ser o texto trabalhado em outras perspectivas - sem contar que esse mesmo eixo prevê "refletir sobre o pré-modernismo em suas dimensões histórica, linguística e social", além da produção individual e coletiva de textos nos gêneros discursivos estudados. Cumpre, nesse ponto, apontar que começamos por destacar essa incongruência apenas por identificar nela o elemento mais visível do problema, que é estrutural e geral.

Comecemos por reparar que os quatro eixos temáticos direcionam o processo de ensino-aprendizagem para a prática da expressão oral, da leitura, da escrita e da análise da língua. São esses os focos de interesse que devem, segundo o espírito do documento, orientar as atividades pedagógicas desenvolvidas no âmbito desses eixos. Vistas por aí, as atividades não tenderão a tomar como prioridade a apreciação estética efetiva do texto literário - ele é sempre assunto para atividades de produção oral e escrita e de análise textual e da língua. Parece-nos, sim, que a conversão do texto literário, no quarto eixo, em material para análise da língua, imediatamente 
após a leitura (idealmente) literária, pode ser um fator desfavorável ao desenvolvimento de uma relação significativa do leitor em formação com a literatura e pode assumir ainda caráter intimidador para o escritor potencial. Mas este é um problema pontual, somente a ponta do iceberg. O que se cristaliza como espírito global da proposta é a instrumentalização geral dos objetos - romances, poemas, charges e cartuns (apresentados como conteúdo pedagógico) - para os exercícios de produção oral e escrita, de leitura e de análise da língua. Basta considerar, ainda a propósito do quarto eixo, o significado do exercício de "reescrever" textos literários quando o que está mais próximo e fresco na mente dos educandos é o substrato gramatical (sintaxe, ortografia etc.) desses textos de onde vem o estímulo. $\mathrm{O}$ objeto da imitação didática será mais provavelmente a arquitetura literária, ou a norma associada à variante linguística dissecada no texto?

Com efeito, não fica estimulada, no conjunto da concepção curricular manifesta no documento, a exploração efetiva dos modos especíicos pelos quais os diferentes gêneros, em função de seus padrões particulares de organização formal, de realização estética e de mobilização de recursos de linguagem, produzem sentidos que Ihes são próprios. Não se propicia, portanto, a apreensão substancial desses gêneros enquanto forma e função. Talvez inicialmente isso pareça um exagero, dado que no eixo de leitura está prevista a "interpretação" dos textos, assim como "Ler associativa e comparativamente os gêneros em estudo, observando forma, conteúdo, estilo e função social". Mas o sentido efetivo dessas indicações depende do que se quer dizer por "interpretar" - o próprio texto esclarece: "interpretar" significa"formular hipóteses (antecipação e inferência)" e"verificar hipóteses (seleção e checagem)". Ora, os autores do documento parecem não se dar conta de que "formular" e "verificar" hipóteses, não sendo postos ab initio no contexto de uma discussão especificamente estético-literária, não prepara e não direciona na prática a apreciação literária para a tomada de consciência nem da "forma", nem do "estilo", nem da "função social" - resta o "conteúdo", ou seja, a dimensão menos propriamente literária do texto literário, e é nesse âmbito que as inferências tenderão provavelmente a ser feitas e testadas.

Pelo seu valor de face, é boa a formulação do eixo "Prática de escrita", que postula a produção de poemas, charges etc., observando seus "elementos constitutivos" - nomeadamente "forma, estilo e conteúdo". Mas, sabendo que é a leitura que provê os estímulos para a escrita, e considerando que, como acabamos de argumentar, a leitura, adotada a orientação fornecida, termina por perder a dimensão estético-literária, inclinando-se antes para interpretações particularmente circunscritas no plano do conteúdo, o mais 
provável é que também a prática de escrita permaneça aquém de uma efetiva apreensão e internalização dos procedimentos literários.

Curiosamente, a palavra letramento nem sequer aparece no documento de Língua Portuguesa. Consta muito embora, repetidas vezes, no Currículo Referência de História. Ali figura, como referencial teórico, um artigo de Magda Soares, intitulado "Letramento e alfabetização: as muitas facetas". Em contraste, salta aos olhos que o referencial bibliográfico utilizado para a elaboração do Currículo Referência de Língua Portuguesa consiste quase que exclusivamente de trabalhos da área da linguística. Além, claro, dos documentos federais e estaduais.

Há, ainda, um último documento que é necessário mencionar, ainda que de passagem: o Relatório de análise de propostas curriculares de ensino fundamental e ensino médio, organizado por Maria das Mercês Ferreira Sampaio e produzido por uma equipe coordenada por ela, após o estado de Goiás Ihe enviar alguns documentos para análise. Muitos desses documentos eram referentes ao EF e por isso não são tratados aqui, já que o nosso destaque é o Ensino Médio. No que nos interessa, esse relatório apresenta uma rápida análise do documento Ressignificação do Ensino Médio: Um caminho para a Qualidade, de 2008, que também é mencionado no documento Referenciais Curriculares - Ensino Médio do Estado de Goiás, mas não encontramos nele nada que mereça destaque especial. Com efeito, a Literatura não aparece de forma substancial em nenhum dos documentos relacionados - inclusive neste relatório.

Podemos, entretanto, tentar entender o que foi o Programa Ressignificação do Ensino Médio, recorrendo à dissertação de mestrado de Vinícius Duarte Ferreira, que trata do processo de Reformulação Curricular do Ensino Médio no Estado de Goiás:

O ProREM surgiu no Estado de Goiás de modo singular quanto aos processos e articulações com a legislação e com a participação das escolas de ensino médio. Suas discussões se iniciaram no ano de 2007 e sua primeira ação efetiva foi a realização, em 2008, do Seminário Realidade e Desafios do Ensino Médio na Atualidade 3 , quando vários alunos e gestores apresentaram suas propostas e anseios diante dos problemas relacionados ao ensino médio em Goiás. Nesse mesmo momento, a SEDUC/GO aproveitou para apresentar as prerrogativas teóricas que serviriam de base para a elaboração do Programa ${ }^{4}$. Ainda no ano de 2008, seis escolas serviram de projeto piloto para as concepções pedagógicas que estavam sendo discutidas (FERREIRA, 2014, p. 58).

O autor esclarece que esse programa teve a adesão de 182 escolas no ano de 2008. Mas, com a mudança de governo, no ano de 2011 o programa 
deixou de existir e toda a equipe da secretaria que havia sido responsável por esse programa foi substituída.

No ano de 2009, a Superintendência de Ensino Médio elaborou o documento "Ressignificação do ensino médio: um caminho para a qualidade", que reunia toda a experiência acumulada nos anos anteriores (GOIÁS, 2009). De acordo com esse documento, era preciso justificar o esforço que a SEDUC/GO estava desprendendo [sic] para reformular essa etapa da educação básica. Além das constantes críticas por parte das comunidades escolares, tais como excesso de burocracia, ausência de formação continuada para professores, desorganização do trabalho docente, inexistência de materiais pedagógicos, dentre outras, a gestão estadual sinalizou para a necessidade dos órgãos públicos em ampliar o diálogo com a comunidade (FERREIRA, 2014, p. 59).

O documento analisado pelo autor já não consta na página da Secretaria de Estado de Educação, Cultura e Esporte, no entanto, foi possível encontrar um livro organizado, ao que parece, a partir dos debates acontecidos durante a existência do programa estudado por Ferreira. É desse material a informação que segue: "No aspecto da distribuição de disciplinas, como caso das Optativas (Artes Cênicas na Literatura I e II, Educação Ambiental I e II, Geometria I e II, Informática no Cotidiano I e II), além da separação de Literatura e Redação de Gramática, obteve-se 65 \% respostas positivas" (ABREU, 2009, p. 153).

Na análise do programa apresentada por Ferreira, tem-se:

Conforme identificamos na pesquisa empírica, nas discussões ao longo da implementação do programa, as escolas da rede pública de Goiás foram adequando suas práticas a essas diretrizes de acordo com suas disponibilidades. No caso das disciplinas opcionais, por exemplo, havia falta de espaço e recursos para a realização das mesmas. Mesmo que os idealizadores do Programa atuassem junto à SEDUC/GO, existiam dificuldades que somente poderiam ser resolvidas com amplos investimentos, o que não havia (FERREIRA, 2014, p. 63).

Ferreira não tratou especificamente das disciplinas e, por essa razão, não era possível saber quais eram. Mas, no artigo da professora Abreu (2009), fica clara a presença da Literatura em, pelo menos, dois âmbitos: nas disciplinas Artes Cênicas na Literatura I e II e, ainda, Literatura, separada de Redação e Gramática. Não foi possível ter acesso às ementas dessas disciplinas. Também não foi possível verificar como se deu a implementação dessas disciplinas nas escolas, mas a citação acima revela a dificuldade material de sua efetiva implementação. O que se tem hoje é a história de um projeto encerrado por conta de mudança de governo. E, se nosso interesse é entender 
o papel que a Literatura ocupa nas grades curriculares no Ensino Médio em Goiás, o único documento que consta na página da secretaria e que permite compreender que papel é esse é o Currículo Referência da Rede Estadual de Educação de Goiás. Esse documento, ainda em fase experimental e quiçá nunca saia dessa fase, é, no âmbito estadual, o que está disponível na página da Secretaria do Estado de Goiás.

Dados o recorte proposto para este trabalho e o percurso traçado, reafirmamos nossa preocupação com o teor das orientações e referências curriculares estaduais no que concerne ao ensino de Literatura, mesmo com as informações incompletas a que nos foi possível ter acesso. Talvez existam outros documentos, não disponibilizados eletronicamente, mas, de todo modo, parecem-nos suficientemente eloquentes os documentos analisados eles não propiciam, no nosso entendimento, um ensino de literatura e leitura capaz de atender minimamente à demanda de um letramento efetivo, pelo qual os educandos se apropriem dos produtos de linguagem socialmente disponíveis e tornem-se capazes de apreciá-los criticamente.

Pode ser - talvez pensássemos - que a presença, em maior número, na equipe de elaboração de documentos dessa ordem, de educadores especialistas nos Estudos Literários contribuísse para o estabelecimento de um quadro melhor. No entanto, as determinações práticas de qualquer processo de elaboração de políticas públicas constituem uma equação imprevisível o bastante para desaconselhar especulações.

Este estudo certamente não esgota, em sua análise, todos os aspectos dos documentos de que tratamos. Como em todo estudo desta ordem, selecionamos o que nos pareceu significativo, enfatizando o que consideramos representativo do teor da proposta. Novos estudos do tema são, portanto, bem-vindos. No ponto a que chegamos, entretanto, podemos resumir como segue as nossas conclusões.

Embora os gêneros literários apareçam em proporção significativa no conjunto dos gêneros discursivos tornados conteúdos curriculares, nossa análise detecta a efetiva ausência de discussão do letramento literário nas orientações estaduais para o Ensino Médio, bem como de qualquer perspectiva de reconhecimento de especificidades distintivas que impusessem tratamento diferenciado dos textos literários, de um lado, e não literários, de outro. Pode-se dizer que a literatura está presente como quantidade no projeto curricular do Ensino Médio, mas não como qualidade. Com efeito, a presença da literatura é constante, mas difusa, dissolvendo-se como conjunto inespecífico de gêneros dentro de um conjunto maior de gêneros indistintos, todos mobilizados por igual em atividades de produção 
textual e de análise textual que não põem em causa a especificidade do fenômeno literário, nem sequer para criticá-la ${ }^{5}$. Trata-se, de fato, de um ponto cego. Enfim, tudo indica que, nos documentos estaduais de Goiás que analisamos, a literatura tem presença possivelmente mais problemática até do que nos documentos federais com que os cotejamos, apesar de todos os problemas nestes observados.

Parecem-nos, pois, imperativos os esforços de busca de caminhos que nos ensejem ultrapassar a redução do texto literário, de um lado, a mero veículo de conteúdos (sejam imaginativos ou realistas, não importa) e, de outro, a mero instrumento no ensino de língua portuguesa. O desenvolvimento da capacidade de fruição e apreciação estética demanda o trato da obra literária em sua totalidade específica. E depende da construção de horizontes de leitura nos quais os educandos possam descobrir, livre e criativamente, por si ou com a mediação do professor, possibilidades outras de construção de sentido, diferentes das imediatamente disponíveis no cotidiano, a partir de seus embates (não instrumentalizados para outros fins) com o texto literário como tal. Nesse ponto, é possível dizer que a apreciação dos documentos que analisamos os surpreende no vermelho inclusive, por não aproveitarem o potencial formativo da Literatura enquanto tal para a formação do sujeito humano, social, ético.

\section{LITERATURE IN THE DOCUMENTS RELEASED BY THE SECRETARY OF EDUCATION, CULTURE AND SPORTS OF THE STATE OF GOIÁS}

ABSTRACT: The purpose of this work was to assess public policy on education, in the State of Goiás, by collating the official guidelines for high-school curriculum released by SEDUCE — Secretaria de Educação, Cultura e Esportes - with related documents, such as the PCN and the OCN, released by the Federation. This comparison revealed a lack of debate and horizons for the literary literacy in the official guidelines for the State of Goiás. Furthermore, the instrumentalization of literary works as a means for teaching language and grammar stands out in the content matrices.

KeYwords: Literature. High-school Education. Curriculum. Public Policy on Education. 


\section{LA LITERACIDAD LITERARIA EN LA ENSEÑANZA SECUNDARIA EN GOIÁS:CRÍTICA DE LAS ORIENTACIONES Y REFERENCIAS CURRICULARES ESTADUALES}

RESUMEN: Esta investigación tuvo como objetivo cotejar los documentos divulgados por la Secretaría de Estado de Educación, Cultura y Deporte de Goiás que tienen como propósito presentar orientaciones curriculares para la enseñanza secundaria con otros documentos relacionados, tales como los Parámetros Curriculares Nacionales (PCNs) y las Orientaciones Curriculares Nacionales (OCNs). El resultado de ese cotejo de documentos demuestra la ausencia de discusión o perspectiva para la literacidad literaria en las orientaciones estaduales para la enseñanza secundaria. Pero, no solo esto: el uso de la literatura como pretexto para la enseñanza de gramática y lengua portuguesa es visible en las matrices de contenidos.

Palabras clave: Literatura. Enseñanza Secundaria. Currículo. Políticas Públicas en Educación.

\section{NotAS}

1 Em um minucioso estudo de Marcia de Paula Gregorio Razzini, intitulado "O espelho da nação: a antologia nacional e o ensino de português e de literatura (1838-1971)", temos acesso à seguinte informação: somente em 1899 que a disciplina Literatura surge no Brasil. De 1857 até 1899 uma série de disciplinas foram ministradas, tais como: a) Literatura nacional; b) Literatura em geral e especialmente a portuguesa e nacional; c) Literaturas estrangeiras; d) História da literatura portuguesa e história da literatura brasileira; e) História literária; f) História da literatura nacional; g) História da literatura geral e da nacional e, em 1899, tem-se: Literatura. Em 1926, tem-se Literatura das línguas latinas e Literatura brasileira.

2 Essa onipresença do literário foi o que nos motivou a tomar como exemplo esse bimestre - seria ele, em tese, o mais propício à abordagem da dimensão especificamente literária do texto literário. A regra geral, ao contrário, é figurarem os gêneros literários e não literários lado a lado no programa.

3 Esse seminário foi realizado na cidade de Pirenópolis - GO. Consideramos a primeira ação do ProREM porque, nesse momento, surge a palavra "ressignificação" e há um avanço no sentido de promover o programa no estado. Contudo, as reuniões e seminários vinham ocorrendo desde 2006. Podemos destacar as duas reuniões ocorridas em Caldas Novas com a presença de coordenadores e diretores das escolas estaduais, onde foram apresentadas as primeiras ideias com relação à reformulação curricular. Posteriormente, houve debates com as entidades/instituições educativas do estado (SEP, Sinep, Sintego, Sipro, Sesi/Senai, Senac/Sesc, MEC, CEE, UEG, UFG, UCG) - a nota é do autor da dissertação (FERREIRA, 2014, p. 58). 
4 De acordo com Moreira (2009), a SEDUC realizou, em Caldas Novas, vários debates nos anos de 2006 e 2007 com o objetivo de trocar experiências e receber sugestões das unidades escolares com relação ao ensino médio. No ano de 2007 houve um amadurecimento das discussões realizadas no ano anterior, o que, inclusive, serviu de orientação para as experiências piloto em 2008 - a nota é do autor da dissertação (FERREIRA, 2014, p. 58).

5 A problematização do próprio conceito de "literatura" e dos processos da "vida literária", que nos levariam a tantas outras questões, como, por exemplo, "cânone", "mercado", "indústria cultural" - e até "ensino de literatura", por que não -, é não apenas cabível, mas seria louvável. Está, porém, distante do horizonte das concepções teóricas que transparecem nos documentos analisados

\section{REFERÊNCIAS}

ABREU, M. do C. R. Ressignificação: ensino médio em travessia: lições aprendidas a partir de encontros e desencontros . In: MOREIRA, M. E. (Org.) Ressignificação: ensino médio em travessia. Goiânia: Kelps, 2009.

BRASIL. Linguagens, códigos e suas tecnologias. In: Orientações Curriculares para o Ensino Médio. Ciências Humanas e suas Tecnologias / Secretaria de Educação Básica. Brasília: Ministério da Educação, Secretaria de Educação Básica, 2006.

. MEC. Secretaria de Educação Média e Tecnológica. Parâmetros curriculares nacionais: ensino médio. Brasília, 1999.

. Relatório de análise de propostas curriculares de ensino fundamental e ensino médio / Maria das Mercês Ferreira Sampaio (organizadora). Brasília: Ministério da Educação / Secretaria de Educação Básica, 2010. 445 p.

FERREIRA, V. D. O Programa Ressignificação do Ensino Médio. In: Reformulação curricular do ensino médio no Estado de Goiás. 2014. 128 f. Dissertação (Mestrado em Educação) - Universidade Federal de Goiás, Regional Catalão, Departamento de Educação, 2014. Disponível em: <https://mestrado_educacao.catalao.ufg.br/up/549/o/ Ferreira_Vin\%C3\%ADcius_Duarte.pdf>. Acesso em: 27 out. 2017.

GOIÁS. Currículo Referência da Rede Estadual de Educação de Goiás - Versão Experimental. S/d. Disponível em: <http://www.seduc.go.gov.br/imprensa/documentos/Arquivos/Curr\%C3\%ADculo\%20Refer\%C3\%AAncia/ Curr\%C3\%ADculo\%20Refer\%C3\%AAncia\%20da\%20Rede\%20Estadual\%20de\%20 Educa\%C3\%A7\%C3\%A30\%20de\%20Goi\%C3\%A1s!.pdf>. Acesso em: 3 nov. 2017.

. Referenciais Curriculares Ensino Médio do Estado de Goiás. Organizadores: Marcos Elias Moreira e Maria do Carmo Ribeiro Abreu. Goiânia, 2009. Disponível em: <http://www.educacao.go.gov.br/documentos/reorientacaocurricular/medio/ diretrizes.pdf>. Acesso em: 20 nov. 2017. 
RAZZINI, M. de P. G. História da disciplina Português na escola secundária brasileira. Revista Tempos e Espaços em Educação, Universidade Federal do Sergipe. Núcleo de Pós-graduação em Educação, v.4, p. 43-58, jan./jul. 2010.

. O espelho da Nação: a "Antologia Nacional" e o ensino de português e literatura (1838-1971). Tese (Doutorado em Estudos da Linguagem) - Instituto de Estudos da Linguagem, Universidade Estadual de Campinas, Campinas, SP, 2000. Disponível em: http://www.unicamp.br/iel/memoria/projetos/teses/tese21.doc Acesso em: 13 jul. 2018.

Cleiry de Oliveira Carvalho: Doutoranda do Programa de Pós-Graduação em Literatura da Universidade de Brasília $\left(U_{n} B\right)$, possui graduação (2001) e mestrado (2007) em Letras pela Universidade Estadual de Maringá. No magistério atuou na condição de professora-formadora na Secretaria de Educação de Marabá/PA (2008-2010). Lá, participou de um projeto de Políticas Públicas destinado à Educação que tem por nome: Extensão universitária em Gestão da Aprendizagem Escolar II - Língua Portuguesa (GESTAR II), proposto pelo MEC em parceria com a UnB. Durante esse período atuando na Secretaria de Educação de Marabá, também atuou em uma faculdade privada (Metropolitana/ Uniasselvi), no curso de Letras. Assumiu, nos últimos meses residindo em Marabá (agosto 2009 - maio 2010), aulas no Ensino Médio após aprovação em concurso público estadual. Em Goiânia trabalhou na UNIP (2011) e na Faculdade de Educação/UFG (2012-2013). Também participou de organização de eventos acadêmicos na UFG. Além de atuar na docência desenvolveu pesquisas nos seguintes temas: distribuição de livros, consumo e entretenimento, literatura narrativa de massa, indústria cultural, formação do leitor e alguma produção de análises de obras de autores consagrados da Literatura Brasileira. Atualmente mantém interesse acadêmico pelas relações entre literatura, sociedade, cultura, história, política e formação social, sobretudo no Brasil.

E-mail: cleirycarvalho@yahoo.com.br 
CÁSSIO TAVARES: Doutor em Teoria Literária e Literatura Comparada pela USP (2003), com pós-doutorado na UnB (2006-2007). Tem especial interesse na relação entre forma estética, forma social, ideologia, hegemonia e mudança histórica; também atua na educação popular, com ênfase na formação política e artístico-cultural da classe trabalhadora. Foi professor da UFPA entre 2007 e 2010, onde atuou nos cursos de Letras e de Licenciatura em Educação do Campo. Atualmente é professor do Departamento de Estudos Literários da Faculdade de Letras da UFG. Colabora com diferentes movimentos populares e sindicatos, continuando a desenvolver atividades de extensão de caráter formativo, direcionadas a ou em parceria com essas organizações. Entre 2015 e 2017 fez em São Paulo o curso de formação de monitores do Núcleo de Educação Popular 13 de Maio (NEP13).

E-mail: cassio.ufs@gmail.com 